\title{
ANALISANDO A GESTÃO EDUCACIONAL EM UMA ESCOLA PÚBLICA: O ATENDIMENTO AOS ALUNOS COM ALTAS HABILIDADES/SUPERDOTAÇÃO
}

\author{
Tatiane Negrini \\ Soraia Napoleão Freitas
}

\section{Resumo}

Este artigo pretende apresentar algumas discussões que permearam a pesquisa realizada no Curso de Especialização em Gestão Educacional, da Universidade Federal de Santa Maria, que teve como objetivo geral investigar como uma escola, através do processo de gestão educacional, organiza suas propostas administrativas e pedagógicas, para promover o desenvolvimento das potencialidades dos alunos com características de altas habilidades/superdotação. Esta pesquisa segue uma abordagem qualitativa, do tipo Estudo de Caso e foi realizada em uma escola pública da cidade de Santa Maria/RS que possui alunos identificados com características de altas habilidades/superdotação. Como instrumento de pesquisa foi utilizada uma pesquisa documental, com a análise do Projeto Político-Pedagógico e do Regimento da escola, sendo também realizadas entrevistas semiestruturadas com os professores que possuem alunos com altas habilidades/superdotação e uma entrevista semiestruturada com um membro da equipe coordenadora da escola. Também foram realizadas observações nas salas de aula destes professores entrevistados. Este estudo fundamentou-se em publicações do MEC (1995, 2001), como também como autores como Renzulli (2004), Libâneo, Oliveira, Toschi (2005), Lück, (2006), Aranha (2005), entre outros.

Palavras-chaves: Gestão educacional; Escola pública; Altas habilidades/superdotação.

\section{ANALYZING THE EDUCATIONAL MANAGEMENT IN A PUBLIC SCHOOL: THE ATTENDANCE TO THE PUPILS WITH HIGH ABILITIES/GIFTEDNESS}

\begin{abstract}
This article intends to present some quarrels that permearam the research carried through in the Course of Specialization in Educational Management, of the Federal University of Saint Maria, who had as objective generality to investigate as a school, through the process of educational management, organize its administrative and pedagogical proposals, to promote the development of the potentialities of the pupils with characteristics of high abilities/giftedness. This research follows a qualitative boarding, of the type Study of Case and was carried through in a public school of the city of Maria/RS Saint that possesss pupils identified with characteristics of high abilities/giftedness. As research instrument was used a documentary research, with the analysis of the Project Pedagogical-Politician and the Regiment of the school, being also carried through interviews half-structuralized with the professors who possess pupils with high abilities/giftedness and an interview half-structuralized with a member of the coordinating team of the school. Also comments in the classrooms of these interviewed professors had been carried through. This study it was based on publications of the MEC $(1995,2001)$, as well as as authors as Renzulli (2004), Libâneo, Oliveira, Toschi (2005), Lück, (2006), Spider (2005), among others.
\end{abstract}

Key-words: Educational management; Public school; High Abilities/Giftedness. 


\section{T. Negrini; S. Napoleão Freitas}

\section{Introdução}

Tem-se conhecimento que a modalidade Educação Especial abrange muitas pessoas, com diversas necessidades educacionais especiais, sendo que inclui também a educação de pessoas com características de altas habilidades/superdotação (AH/SD), segundo a Política Nacional de Educação Especial na Perspectiva da Educação Inclusiva (2008). Estes indivíduos, que muitas vezes passam por vários obstáculos, entre eles o da sua identificação, carecem de um ambiente estimulador e desafiante, para instigá-las a buscar novos conhecimentos e não correr o risco de adormecerem seus talentos.

Portanto, baseando-se nas normas atuais da educação inclusiva, as escolas devem estar preparadas para receber e atender essas crianças, que além do acesso à escola, necessitam de uma educação de qualidade. Dessa forma, sabe-se que as escolas, ao terem identificado em suas instituições alunos com características de altas habilidades/superdotação, devem se organizar para estimular o conhecimento dessas pessoas, através de políticas e práticas desenvolvidas em cada escola, de acordo com a sua realidade. As políticas públicas educacionais também abordam a temática da educação especial e das altas habilidades/superdotação, e apontam algumas características destes alunos e algumas formas de atendimento.

Assim, este artigo apresenta algumas discussões realizadas na pesquisa desenvolvida no Curso de Especialização em Gestão Educacional, da Universidade Federal de Santa Maria, a qual teve como objetivo geral investigar como uma escola, através do processo de gestão educacional, organiza suas propostas administrativas e pedagógicas, para promover o desenvolvimento das potencialidades dos alunos com características de altas habilidades.

\section{Artefatos Metodológicos}

Com a delimitação do problema e dos objetivos da pesquisa, que necessariamente estão relacionados com uma realidade socialmente vivenciada, procura-se apresentar os caminhos metodológicos que guiaram esta investigação. De acordo com Minayo (1994, p. 16), "a metodologia inclui as concepções teóricas de abordagem, o conjunto de técnicas que possibilitam a construção da realidade e o sopro divino do potencial criativo do investigador". Por este motivo, a metodologia, contando com todo este aparato, apresenta com clareza processos coerentes e bem elabora- 
dos, que conduzem os obstáculos teóricos para o esclarecimento na prática.

Esta pesquisa segue uma abordagem qualitativa, pois se preocupa com o conjunto de significados e aspirações envolvidas no processo. Segundo Minayo (1994, p. 22), “a abordagem qualitativa aprofunda-se no mundo dos significados das ações e relações humanas, um lado não perceptível e não captável em equações, médias e estatísticas".

Dessa forma pressupõe o uso da subjetividade para a explicação da realidade social, sendo um de seus pontos marcantes a flexibilidade de formulação e reformulação de hipóteses. Geralmente na pesquisa qualitativa segue-se o mesmo caminho para a investigação, escolhendo um problema, realizando a coleta de dados e a análise das informações. Porém esta sequência não é tão rígida no seu desenvolvimento, podendo não segregarse em etapas estanques (TRIVIÑOS, 1987).

Esta investigação caracteriza-se também como um estudo de natureza descritiva, pois como traz Triviños (1987, p. 110), "pretende descrever 'com exatidão' os fatos e fenômenos de determinada realidade". O estudo descritivo procura conhecer uma realidade, suas características, seus acontecimentos e fatos importantes.

As pesquisas deste tipo têm como objetivo primordial a descrição das características de determinada população ou fenômeno ou o estabelecimento de relações entre variáveis. São inúmeros os estudos que podem ser classificados sob este título e uma de suas características mais significativas está na utilização de técnicas padronizadas de coleta de dados (GIL, 1994, p. 45).

Alguns estudos descritivos podem ser denominados de Estudos de Casos, como é o caso desta pesquisa, uma vez que pretende aprofundar os conhecimentos e a descrição sobre determinada realidade. No estudo de caso os resultados são válidos apenas para o caso em estudo, não se podendo fazer generalizações dos resultados alcançados. Ao mesmo tempo, ao fazer o aprofundamento de um caso, os resultados podem permitir a formulação de hipóteses para o encaminhamento de outras pesquisas (TRIVIÑOS, 1987).

Este Estudo de Caso foi realizado em uma instituição pública de ensino pertencente à cidade de Santa Maria/RS que possui alunos identificados com características de altas habilidades/superdotação. Nesta escola foram desenvolvidos projetos para a identificação de alunos com características de altas habilidades/superdotação e para tanto, aconteceu um esclareci- 


\section{T. Negrini; S. Napoleão Freitas}

mento para professores e direção sobre o tema em questão. No ano da realização da pesquisa os alunos identificados na escola participavam do PIT - Programa de Incentivo ao Talento, que é um projeto de extensão da UFSM.

Buscou-se então especificar alguns instrumentos de pesquisa, sendo que foi realizada uma pesquisa documental, com a análise do Projeto Político-Pedagógico (PPP) da escola, pois neste documento consta a organização pedagógica e administrativa da escola, assim como do Regimento Escolar.

Além disso, para a coleta de dados foram utilizadas entrevistas semiestruturadas com os professores das séries iniciais que possuem em suas turmas alunos com características de altas habilidades/superdotação que participam do Programa de Incentivo ao Talento, e uma entrevista semiestruturada com um membro da equipe coordenadora da escola. Foram realizadas também algumas observações nas salas de aula destes professores entrevistados. Com isso buscou-se alcançar respostas ao problema desta pesquisa e aos objetivos almejados, sendo que delas podem surgir outros questionamentos.

\footnotetext{
Mas, sem dúvida alguma, o pesquisador qualitativo, que considera a participação do sujeito como um dos elementos de seu fazer científico, apóia-se em técnicas e métodos que reúnem características sui generis, que ressaltam sua implicação e da pessoa que fornece as informações. Neste sentido, talvez sejam a entrevista semi-estruturada, a entrevista aberta ou livre, o questionário aberto, a observação livre, o método clínico e o método de análise de conteúdo os instrumentos mais decisivos para estudar os processos e produtos nos quais está interessado o investigador qualitativo (TRIVIÑOS, 1987 , p. 138) (grifos do autor).
}

A pesquisa documental foi utilizada nesta investigação tendo em vista que seria possível conhecer melhor a realidade onde estava sendo realizado o Estudo de Caso, seus objetivos de trabalho, seus planejamentos, suas ações e suas aspirações quanto ao que a escola almeja e o que está fazendo para atingir os objetivos traçados. Neste sentido, a escola disponibilizou para consulta o PPP e o Regimento Escolar.

A pesquisa documental assemelha-se muito à pesquisa bibliográfica. A única diferença entre ambas está na natureza das fontes. Enquanto a pesquisa bibliográfica se utiliza fundamentalmente das contribuições dos 
diversos autores sobre determinado assunto, a pesquisa documental vale-se de materiais que não receberam ainda um tratamento analítico, ou que ainda podem ser reelaborados de acordo com os objetivos da pesquisa (GIL, 1994, p. 73).

A entrevista foi escolhida como instrumento de coleta de dados tendo em vista que o fato de que o entrevistador estando à frente do entrevistado facilita a obtenção de informações que interessem à investigação, uma vez que se trata de uma forma de interação social. Além disso, é uma técnica eficiente para obtenção de dados em profundidade acerca do que está sendo pesquisado (GIL, 1994). Acredita-se que a entrevista seja uma das ferramentas que se pode utilizar com intuito de obter informações acerca do que as pessoas pensam, acreditam, sabem.

\begin{abstract}
A entrevista é uma das técnicas de coleta de dados mais utilizada no âmbito das ciências sociais. Psicólogos, sociólogos, pedagogos, assistentes sociais e praticamente todos os outros profissionais que tratam de problemas humanos valem-se dessa técnica, não apenas para coleta de dados, mas também com objetivos voltados para diagnóstico e orientação (GIL, 1994, p. 113 ).
\end{abstract}

A entrevista foi elaborada tendo em vista os objetivos da pesquisa, a fim de investigar algumas questões pertinentes. As perguntas foram descritivas, sendo que a partir delas, surgiram novas perguntas que vieram ao encontro da pesquisa. É importante salientar que as entrevistas foram realizadas individualmente, para que se obtivessem respostas fidedignas do professor entrevistado.

O registro das entrevistas foi realizado com a gravação das respostas do entrevistado, com sua permissão, sendo que posteriormente foram transcritas. Nos casos em que não houve permissão, foi feita a anotação das informações ao mesmo tempo em que a entrevista estava sendo realizada.

As observações foram descritas em anotações de campo, conforme traz Triviños (1987). Nas anotações de campo foram descritas as observações e reflexões realizadas sobre as expressões e ações dos sujeitos, descrevendo-as e fazendo comentários sobre as mesmas, assim como anotando os aspectos mais pertinentes referentes à pesquisa.

Foram escolhidas as estratégias metodológicas citadas, pelo fato de se considerar estas as melhores opções para se conseguir informações autênticas, que realmente estão relacionadas com o intuito desta pesquisa. 
Após a obtenção dos dados foi realizada a análise do material obtido, para discriminar e selecionar as informações coletadas que vieram ao encontro do problema que se propôs esta pesquisa. A análise dos dados segue o método de Análise do Conteúdo, apresentado por Bardin (2004).

A análise do conteúdo é denominada como um grupo de técnicas de análise das comunicações. De acordo com Bardin, a análise do conteúdo pode ser designada da seguinte forma:

[...] um conjunto de técnicas de análise das comunicações visando obter, por procedimentos sistemáticos e objectivos de descrição do conteúdo das mensagens, indicadores (quantitativos ou não) que permitam a inferência de conhecimentos relativos às condições de produção/recepção (variáveis inferidas) destas mensagens (2004, p. 37).

Na análise do conteúdo não existe um "pronto-a-vestir", mas somente algumas regras básicas que podem ser seguidas. É um método muito empírico, que depende do tipo de comunicação a que se dedica e da interpretação que se pretende como objetivos (BARDIN, 2004).

Este tipo de análise pode ser utilizado tanto em pesquisas quantitativas quanto qualitativas. Como este estudo trata-se de uma pesquisa qualitativa, Bardin (2004, p. 107) salienta que neste caso "[...] recorre a indicadores não frequenciais susceptíveis de permitir inferências; por exemplo, a presença (ou a ausência) pode constituir um índice tanto (ou mais) frutuoso do que a frequência de aparição”. Assim, esta pesquisa não pretende fundamentar-se na frequência de aparição de alguns elementos, mas na sua aparição ou não nas comunicações analisadas.

Acredita-se que a utilização da pesquisa qualitativa e das metodologias citadas para a coleta de dados, tenha proporcionado uma discussão da problemática em questão, indicando novos aspectos relacionados à gestão educacional e à educação de alunos com características de altas habilidades/superdotação.

\section{Discussão teórico-prática}

$\mathrm{Na}$ área das altas habilidades, o embasamento teórico utilizado nesta pesquisa relaciona-se com autores que descrevem as características dos alunos com altas habilidades/superdotação, assim como as políticas educacionais internacionais, nacionais e estaduais que tratam a respeito estes 
alunos, algumas delas garantindo um atendimento diferenciado.

A escola, como uma organização complexa que trabalha com a perspectiva de desenvolver as capacidades de todos os alunos que se encontram naquele ambiente, deve reconhecer as diferenças de cada um deles, respeitando-as. O reconhecimento das necessidades dos alunos faz com que a instituição escolar inclusiva possa oferecer subsídios para que estes progridam social, cognitiva, afetiva e culturalmente. Estas ações devem estar embasadas nas experiências escolares e nas legislações públicas, que garantem o direito dos indivíduos a uma educação de qualidade.

Pensando nessas colocações, as pessoas com características de altas habilidades/superdotação precisam ser reconhecidas neste ambiente escolar, uma vez que desta maneira se estará reconhecendo sua diferença. Com o reconhecimento de suas características, se poderá organizar ações para atender suas necessidades.

Com isso é necessário esclarecer o que a legislação pública educacional, assim como alguns pesquisadores da área, apresentam sobre as altas habilidades/superdotação, sendo que nos documentos legais existem algumas definições do que são as altas habilidades/superdotação. O Ministério da Educação e do Desporto, na Publicação "Diretrizes Gerais para o Atendimento Educacional aos Alunos Portadores de Altas Habilidades/ Superdotação e Talento" traz a seguinte definição:

Altas Habilidades referem-se aos comportamentos observados e/ou relatados que confirmam a expressão de "traços consistentemente superiores" em relação a uma média (por exemplo: idade, produção, ou série escolar) em qualquer campo do saber ou do fazer. Devese entender por "traços" as formas consistentes, ou seja, aquelas que permanecem com freqüência e duração no repertório dos comportamentos da pessoa, de forma a poderem ser registradas em épocas diferentes e situações semelhantes. Esses educandos apresentam envolvimento com a tarefa, traço que se refere a comportamentos observáveis na demonstração de expressivo interesse, motivação e empenho pessoal nas tarefas que realiza em diferentes áreas, e criatividade, traço que diz respeito a comportamentos criativos observáveis no fazer e no pensar, expressados em diferentes formas: gestual, plástica, teatral, matemática ou musical, entre outras. Identificadas necessariamente por profissionais qualificados, Superdotados e Talentosos são indivíduos que, por suas habilidades evidentes, são capazes de alto desempenho (Renzulli. 1988), têm capacidade e potencial para desenvolver esse conjunto de traços e usa-los em qualquer área potencialmente valiosa da realização humana, em qual- 
quer grupo social (BRASIL, MEC/SEESP, 1995, p. 13).

Essa mesma conceituação é encontrada no documento "Programa de Capacitação de Recursos Humanos do Ensino Fundamental: Superdotação e Talento", também do Ministério da Educação e do Desporto. Ambas baseiam-se na definição de Renzulli,como se poderá ver a seguir.

A partir da definição nestes e outros documentos das características dos alunos com altas habilidades/superdotação, pode-se perceber que estes alunos não apresentam um perfil homogêneo, variando de acordo com o contexto sócio-cultural em que estão inseridos.

As legislações mostram que as pessoas com altas habilidades/ superdotação estão incluídas no grupo das pessoas com necessidades educacionais especiais, e assim é necessário que tenham um atendimento diferenciado nas escolas para o seu maior desenvolvimento.

A Resolução CNE/CEB n ${ }^{0}$ 2, de 2001, que institui as "Diretrizes Nacionais para a Educação Especial na Educação Básica” no Artigo $5^{\circ}$ considera educandos com necessidades educacionais especiais os que, durante $o$ processo educacional, apresentarem: "III- altas habilidades/superdotação, grande facilidade de aprendizagem que os leve a dominar rapidamente conceitos, procedimentos e atitudes". Além disso, esta resolução aponta algumas considerações que necessitam ser previstas na organização das classes comuns, para atender as necessidades dos alunos.

Entre muitos pesquisadores da área da superdotação acredita-se que o estudioso Joseph S. Renzulli vem contribuindo de forma significativa na definição de características e na identificação de pessoas com altas habilidades/superdotação. Renzulli (1994) traz que, através das pesquisas na área, se tem ajudado a apontar o caminho para modificações na teoria e na prática.

Segundo Renzulli (1994), existem muitas opiniões diferentes sobre a definição da superdotação, e é assim que deve ser. Com isso, a maneira habitual de medir a superdotação, através dos testes padronizados de Q. I., deixa de ser a única maneira de se conhecer a inteligência de uma pessoa.

Renzulli propõe dois tipos de superdotação: a superdotação acadêmica ou intelectual, e a superdotação produtivo-criativa. A superdotação acadêmica é aquela que pode ser identificada facilmente através dos testes padronizados, sendo o tipo mais valorizado nas escolas tradicionais. É o tipo mais utilizado para selecionar educandos para programas especiais. A superdotação produtivo-criativa, segundo Renzulli (1994), narra aqueles 
aspectos da atividade humana nos quais se incentiva o desenvolvimento de materiais originais, inéditos, expressões artísticas diferenciadas e áreas do conhecimento. Este tipo de superdotação tende a ser contextual e específica de uma área de interesse.

Renzulli, a partir de suas pesquisas com pessoas criativas e produtivas, mostra que não existe um critério simples para indicar a superdotação. As pessoas que tem alcançado reconhecimento apresentam um conjunto de características bem definidas, que se entrelaçam entre si. São elas: Habilidade acima da média, Comprometimento com a tarefa e Criatividade elevada. Este estudo é definido como o Conceito dos Três Anéis.

Quanto ao atendimento destes alunos, as políticas educacionais apresentam várias considerações. Aqui cita-se as Diretrizes Nacionais para a Educação Especial na Educação Básica, que traz em seu artigo 8:

\footnotetext{
Art. 8 - As escolas da rede regular de ensino devem prever e prover na organização de suas classes comuns: IV - serviços de apoio pedagógico especializado, realizado, nas classes comuns, mediante:

a) atuação colaborativa de professor especializado em educação especial;

b) atuação de professores-intérpretes das linguagens e códigos aplicáveis;

c) atuação de professores e outros profissionais itinerantes intra e interinstitucionalmente;

d) disponibilização de outros apoios necessários à aprendizagem, à locomoção e à comunicação (MEC/SEESP, $2001)$.
}

Além da legislação citada, também a LDB nº 9.394/96, o Plano Nacional de Educação (Lei n ${ }^{\circ}$ 10.172, de 2001), a Constituição do Estado do Rio Grande do Sul, (1989), entre outras, salientam as características dos alunos com altas habilidades/superdotação e a organização das escolas e a necessidade de preparação para o atendimento de qualidade para estes alunos. Com o conhecimento da legislação se torna mais fácil a identificação dos alunos, assim como realizar um trabalho diferenciado que vá ao encontro das suas reais necessidades. Por este motivo a gestão escolar deve estar consciente dos dispositivos legais que amparam todos os alunos da escola, a fim de estar contribuindo para seu desenvolvimento cognitivo e social.

Pode-se interpretar que nestas políticas, algumas vezes de maneira geral, em relação à educação especial, em outras em relação aos alunos com altas habilidades/superdotação, estão garantidas algumas formas de atendimento educacional especializado para estes alunos, facilitando seu 


\section{T. Negrini; S. Napoleão Freitas}

acesso ao ambiente escolar e o desenvolvimento de suas potencialidades, através da flexibilização de currículo, suplementação, etc.

Porém é necessário salientar que para os alunos com altas habilidades/superdotação não basta garantir o acesso e o ingresso ao ensino, mas também a qualidade de ensino, a permanência bem-sucedida destes no ambiente escolar com a estimulação e o desenvolvimento de suas habilidades.

De acordo com Pérez, a inclusão do aluno com AH/SD deve garantir não somente a permanência do aluno na escola, mas:

[...] a "permanência" deve ser sempre acompanhada do adjetivo "bemsucedida", porque, especialmente no que se refere ao aluno com $\mathrm{AH} / \mathrm{SD}$, que será o outro filtro que conduzirá essa análise, não é o acesso, o ingresso ou a permanência simples e pura que impede a inclusão desse aluno, mas a qualidade dessa permanência. Se apenas o acesso, o ingresso e a permanência na escola fossem garantia de inclusão, a grande maioria dos milhões de brasileiros com AH/SD que hoje, literalmente, "passa pela escola" (quando não a abandonam), não formaria esse exército de crianças/adolescentes/adultos-fantasmas, obrigados a se adaptarem a um ensino medíocre (ou a revoltar-se contra ele); a terem suas potencialidades ofuscadas. Amordaçadas ou extintas, até, a serem discriminados e, muitas vezes, ridicularizados pelo seu comportamento e, em muitos casos, a serem até medicados para sanar patologias que não possuem (2006, p. 152-153).

Dessa forma, para que realmente se almeje uma inclusão dos alunos com altas habilidades/superdotação, a política deve oferecer subsídios para a permanência bem-sucedida destes alunos na escola, e que as escolas assegurem aos alunos estes suportes educacionais. Percebe-se que nos últimos tempos a inserção dos alunos com altas habilidades/superdotação nas políticas educacionais tem aumentado, porém ainda há desconhecimento por parte dos professores sobre o tema, assim como a falta de aprofundamento na questão, principalmente quanto ao atendimento educacional destes alunos.

Quanto à gestão educacional, trabalha-se com autores como Libâneo, Oliveira, Toschi (2005), Lück, (2006), Aranha (2005), entre outros, com os quais é possível fazer uma articulação com os objetivos deste trabalho.

A escola é uma instituição social educativa que ao longo da história é questionada a respeito de seu papel frente às transformações políticas, sociais, econômicas do mundo moderno. A sociedade passa constantemente 
por avanços tecnológicos, mudanças no mundo do trabalho, nos hábitos de consumo, nas organizações do sistema de produção, e isso vem sendo denominado globalização. Estas transformações refletem-se na realidade escolar, na sua forma de trabalho, na sua gestão educacional.

Diante dos desafios e das revoluções, cabe à escola oferecer subsídios para que essas necessidades sejam supridas, oferecendo respostas à sociedade. A formação de profissionais para o desenvolvimento das habilidades dos sujeitos e para a participação neste processo também são relevantes. Espera-se, assim, incluir o Brasil na economia global competitiva, porém sem sacrificar sua cultura e seus valores. Segundo Libâneo, Oliveira e Toschi (2005, p. 116), "o grande desafio é o de incluir, nos padrões de vida digna, os milhões de indivíduos excluídos e sem condições básicas para se constituírem cidadãos participantes de uma sociedade em permanente mutação".

Dessa forma, a escola pública é levada a pensar sobre diferentes assuntos relacionados aos avanços tecnológicos da sociedade contemporânea e à sua prática pedagógica, tanto em relação à qualidade de ensino, quanto ao acesso de todos os alunos ao conhecimento.

As transformações que vem ocorrendo e sendo impostas ao sistema educacional, exigem formas de organização e gestão definidas e claras, a fim de se atingir os objetivos almejados. De acordo com Libâneo; Oliveira; Toschi, no caso da escola,

[...] a organização e a gestão referem-se ao conjunto de normas, diretrizes, estrutura organizacional, ações e procedimentos que asseguram a racionalização do uso de recursos humanos, materiais, financeiros e intelectuais assim como a coordenação e a acompanhamento do trabalho das pessoas (2005 p. 293).

A organização e a gestão escolar possuem um papel muito importante dentro do contexto escolar, sendo que visam:

a) prover as condições, os meios e todos os recursos necessários ao ótimo funcionamento da escola e do trabalho em sala de aula;

b) promover o envolvimento das pessoas no trabalho, por meio da participação, e fazer a avaliação e o acompanhamento dessa participação;

c) garantir a realização da aprendizagem para todos os alunos (LIBÂNEO; OLIVEIRA; TOSCHI; 2005; p. 294). 
A escola tem se apresentado, assim, como espaço de realização de metas e objetivos pedagógicos. São ambientes formativos, nos quais se podem criar ou modificar modos de agir e pensar das pessoas.

Nesse sentido, a escola - incluindo-se aqui professores, funcionários, pais - é responsável pela inclusão dos alunos no contexto escolar, uma vez que é seu papel promover o desenvolvimento de seus educandos. Cabe colocar que uma escola inclusiva é aquela que, além de receber os alunos, também deve proporcionar condições para seu desenvolvimento nos diferentes níveis, social, intelectual, etc.

Pode-se compreender esta colocação pelo fato de que o sistema de ensino e as políticas educacionais devem ter como referência a escola e a sala de aula. Assim como os profissionais da escola devem ter claro o conjunto do sistema de ensino nacional e estadual, para que possam realizar um trabalho coeso e coerente com as políticas educacionais.

Neste trabalho procurou-se analisar como estão sendo atendidos os alunos com características de altas habilidades/superdotação tanto a nível "macro", de sistema de ensino e políticas educacionais, assim como a nível "micro", no contexto da escola, da sala de aula e do trabalho do professor. A relação entre estes níveis efetiva a organização do sistema de ensino nacional.

Ao serem questionadas sobre o que existe sobre educação especial e altas habilidades/superdotação no PPP da escola, as professoras responderam que:

\footnotetext{
Em relação à educação especial nós temos, ah, temos uma educadora especial na escola, com uma sala de recursos. Isso então está previsto que a escola atende os alunos que tem alguma dificuldade na aprendizagem, dificuldades estas que, assim, como vou te dizer, bastante significativas [...] (Professora G).

Há uma grande preocupação nossa, principalmente nas séries iniciais, que tá iniciando a inclusão na escola. Tem sido feito debates e o pessoal tem chamado pessoas para falar pra gente a respeito disso. Só que eu acho que nós, enquanto professores, vou falar no sentido das séries iniciais, né, não temos habilidade nem habilitação para trabalhar com estas, no caso, com os especiais. Eu acredito, eu sou uma pessoa que não tenho condições de ter um aluno especial, não saberia nem como proceder com esta criança. Por isso eu acho que, deveria, e aqui na escola tem, uma educadora especial para dar este apoio, né. (Professora M).
} 
O membro da coordenação da escola também coloca:

A educação especial, nós temos uma educadora especial, onde é feito um encaminhamento pelos professores da turma, e na verdade ela faz um trabalho de reforço. Nós não temos uma sala especial, nós temos uma sala de recursos, aonde é encaminhado estes alunos com dificuldades de aprendizagem [...] Nas altas habilidades, também a professora educadora especial, ela faz um trabalho, onde detectou, e a partir daí é feito um trabalho bem específico para estes alunos (Professora $\mathrm{C})$.

Especificamente altas habilidades, não. Mas sempre com a educadora especial, sobre a sala de recursos, sim. Sempre é bem colocado e bem reforçado, que é um trabalho que a anos se está fazendo aqui na escola, bem fundamentado. Mas altas habilidades ainda é uma coisa nova, bem nova (Professora C).

Assim, pode-se notar que, segundo o relato das professoras, poucos itens foram acrescentados no PPP da escola que tratam da educação especial, sendo que ao se falar nisso, referem-se como um trabalho desenvolvido somente na sala de recursos e pela educadora especial, apesar de haver uma preocupação com a inclusão escolar. Conforme seus relatos, os professores não se sentem preparados para atender estes alunos nas suas salas, responsabilizando somente a educadora especial por este trabalho.

Pode-se observar que existe uma carência quanto ao aspecto da educação especial no PPP da escola, tendo em vista a inclusão escolar, pois a maior parte das preocupações com os alunos com necessidades educacionais especiais são remetidas a educadora especial. Inclusive o membro da coordenação escolar cita a educadora especial quanto ao trabalho com os alunos com altas habilidades/superdotação, porém no PPP da escola e nem as professores dos alunos comentam que a educadora especial realiza o atendimento a estes alunos.

Não se pode deixar de colocar que a escola é uma organização social, sendo afetada pelas demais estruturas, econômica, social, política, e pelas relações de poder presentes na sociedade. Estas influenciam nas decisões dentro da escola, nas práticas dos professores e nas formas de professores e alunos. 
do sistema de ensino podem exercer forte influência e controle na formação das subjetividades de professores e alunos (LIBÂNEO; OLIVEIRA; TOSCHI; 2005; p. $297)$.

Com isso, os professores devem ter clareza das influências que as questões sociais e políticas têm dentro do contexto administrativo e pedagógico da escola, as quais evidenciam relações de poder, diferentes formas de avaliação do aluno, etc.

A gestão educacional, portanto, abrange "a dinâmica das interações, em decorrência do que o trabalho como prática social passa a ser o enfoque orientador da ação do dirigente, executada nas organizações de ensino de forma compartilhada e em equipe" (LÜCK, 2006, p. 38).

Esta necessidade de rever a concepção de escola, de educação, etc, tem exigido das instituições de ensino um esforço muito grande de organização das ações pedagógicas, sociais e da gestão, a fim de promover a formação dos alunos para a participação na sociedade.

Esta concepção de descentralização do ensino e democratização da escola é um paradigma em processo de transição e que tende a avançar nas formas de organização e gestão educacional. Este entendimento está relacionado à ideia de que cada instituição apresenta características diferentes; de que a escola é uma organização social e por isso tem um processo educacional dinâmico; que os alunos necessitam de um ambiente democrático e participativo para sua formação e; que deve existir uma aproximação entre tomada de decisões e ação, garantindo a adequação das decisões e a efetividade das ações (LÜCK, 2006).

Atualmente as questões sociais e educacionais são muito mais abrangentes, demandando da educação um esforço maior em torno de sua organização, exigindo o empenho de todas as pessoas neste processo, tanto professores, como coordenação, funcionários, alunos e pais.

A partir desta compreensão, e entendendo que este paradigma está em evolução, Lück menciona que,

\footnotetext{
A gestão educacional corresponde à área de atuação responsável por estabelecer o direcionamento e a mobilização capazes de sustentar e dinamizar o modo de ser e de fazer dos sistemas de ensino e das escolas, para realizar ações conjuntas, associadas e articuladas, visando o objetivo comum da qualidade do ensino e seus resultados (LÜCK, 2006, p. 25).
} 
Neste trabalho, utiliza-se o termo gestão educacional fazendo referência à gestão em âmbito macro, tendo em vista os sistemas de ensino, e ao âmbito micro, a partir das escolas. Esta concepção de gestão que vem sendo discutida permeia todos os segmentos do sistema, tanto macro, como micro. Conforme aborda Lück (2006a, p. 26), "torna-se fundamental que se construa uma consistência entre os processos de gestão de sistemas de ensino e o que se espera ocorra no âmbito da escola, mediante uma orientação única e consistente de gestão".

Analisando o PPP e o Regimento Escolar, percebe-se que a modalidade de ensino, a educação especial, é apresentada no Regimento Escolar, constando formas de atendimento, metodologia, avaliação, etc, porém não cita todos os alunos da educação especial e se restringe ao aluno com deficiência mental. Além disso, a educação especial é citada em relação à sala de recursos que a escola possui, mas não coloca a questão da inclusão educacional.

Entende-se que muitos progressos têm acontecido nas práticas das professoras que vão ao encontro da inclusão dos alunos, mas estas práticas ainda não estão propostas nos documentos escolares.

Percebe-se assim que o PPP e o Regimento Escolar, apesar de já apresentarem algumas questões quanto à educação especial, não prevêem um atendimento educacional diferenciado aos alunos com altas habilidades/ superdotação, delimitando o atendimento na sala de recursos ao aluno com deficiência mental. Dessa forma, é importante que aconteçam debates na escola, para que sejam incluídos nestes documentos objetivos que assegurem a inclusão dos alunos com outras necessidades educacionais especiais e para que os professores que trabalham com estes alunos em suas salas de aulas possam sentir-se mais seguros e preparados frente a estes alunos.

Conforme Libâneo, Oliveira, Toschi,

[...] a cada período do ano letivo é avaliado para que se tomem novas decisões, se retome o rumo, se corrijam desvios. Todo projeto é, portanto, inconcluso, porque as escolas são instituições marcadas pela interação entre pessoas, por sua intencionalidade, pela interligação com o que acontece em seu exterior (na comunidade, no país, no mundo), o que leva a concluir que elas não são iguais (2005, p. 361).

De acordo com os autores a avaliação do PPP é necessária para que sejam incluídos nele aspectos que surgem na realidade escolar, que estão sendo discutidos e necessitam de atenção. 


\title{
T. Negrini; S. Napoleão Freitas
}

Ao se discutir a respeito da gestão educacional, não se pode deixar de salientar o importante papel do professor como gestor da sala de aula. A aprendizagem dos alunos é a razão principal da organização do trabalho da gestão da escola, sendo os professores também responsáveis por esta gestão.

De acordo com Aranha,

\begin{abstract}
Reconhecer os docentes como sujeitos do processo de ensino-aprendizagem, como educadores em toda a dimensão do termo, é essencial. Mas reconhecê-los também como gestores ou co-gestores do seu trabalho é a linha divisória entre uma mudança real ou fictícia no interior das escolas (2005, p. 80).
\end{abstract}

Dessa forma, o professor deve ser reconhecido como responsável pelo processo de ensino-aprendizagem dentro da sala de aula, assim como pela gestão do seu próprio trabalho. Por este motivo a inserção do professor na gestão político-pedagógica da escola e nas tomadas de decisões é de fundamental importância, visto as suas experiências e seus saberes.

O trabalho do professor contribui para o funcionamento da escola, sendo necessário que compreendam a necessidade de um trabalho em conjunto com outros colegas e de um bom relacionamento com os demais membros da instituição. Além disso, é necessário que a direção escolar dê condições para o professor consiga realizar um bom trabalho em sala de aula.

Assim, a partir das observações e entrevistas, pode-se notar que os professores sentem-se despreparados para atender estes alunos, desconhecendo de forma clara o assunto. Por este motivo, os alunos que se destacam devem seguir o ritmo da turma, realizando as mesmas atividades, o que por vezes pode levar ao desinteresse do aluno pela aula.

Conforme foi possível perceber, sabe-se que os alunos com altas habilidades/superdotação podem exercer a função de monitores na sala de aula, para que assim ocupem seu tempo livre. Guenther (2000) traz que o tempo que os alunos com altas habilidades perdem esperando os colegas terminarem as atividades precisa ser aproveitado com atividades que sejam úteis para o seu desenvolvimento.

Todavia não é fácil ocupar apropriadamente o tempo de espera, quando ele é intermitente durante um dia escolar, pois não chega a permitir engajamento em algo interessante que efetivamente beneficie a crian- 
Analisando a gestão educacional em uma escola pública

ça mais capaz. Teria que ser uma tarefa chamativa que atraia a atenção da criança, sem ser apenas 'mais do que a escola já faz', nem atividades pueris com função puramente de entretenimento (GUENTHER, 2000, p. 260).

Assim, a autora propõe monitorias, cantinho de "que-fazeres", projetos individuais, entre outras coisas que podem ser realizadas nas salas de aula para o atendimento destes alunos (Guenther, 2000).

Além destas possibilidades, salienta-se que o mais importante é que o aluno com altas habilidades/superdotação faça parte de um ambiente estimulador e desafiante, que o instigue a buscar novos conhecimentos. Partindo destas ideias, o papel do professor em sala de aula influencia no desenvolvimento das habilidades dos alunos, sendo que o atendimento educacional diferenciado contribui com seu crescimento.

Dessa forma, acredita-se que para acontecer uma gestão democrática, os membros escolares devem estar envolvidos com a ação pedagógica, participando das tomadas de decisões e mantendo uma boa relação de diálogo entre si. A gestão estará ạtendendo às necessidades de todos os alunos, no momento que práticas democráticas e coerentes com os objetivos orientadores da escola sejam discutidas coletivamente e realizadas conscientemente.

\section{Considerações finais}

Como foi possível perceber nesta pesquisa, e a partir de alguns aspectos apontados neste texto, as políticas públicas estão estruturadas, a partir dos diferentes acontecimentos sociais, salientando e apresentando dados importantes para as instituições educacionais, uma vez que garantem o direito dos alunos com necessidades educacionais especiais, assim como dos alunos com altas habilidades/superdotação, o acesso à educação e a um ensino de qualidade. Esta qualidade da educação pode ser pensada a partir do estabelecimento de estratégias diferenciadas de reconhecimento, atendimento e respeito às diferenças destes alunos, por meio de adaptações curriculares, práticas diferenciadas dos professores, conforme está previsto nas legislações.

Assim sendo, não basta para o aluno com altas habilidades/ superdotação a garantia de seu acesso ao ensino, caso não haja também condições para a permanência deste no processo, com uma educação de qualidade. Desta maneira estaria, talvez de uma forma diferente daquela 


\section{T. Negrini; S. Napoleão Freitas}

que se concebe, se excluindo novamente este aluno do processo educacional.

Assim, pode-se inferir que neste sentido muitos progressos ainda são necessários, a fim de se definir uma gestão educacional preocupada com a garantia de uma educação de qualidade para todos os alunos.

\section{Referências}

ARANHA, Antônia Vitória Soares. Gestão e organização do trabalho escolar: novos tempos e espaços de aprendizagem. In: OLIVEIRA, Maria Auxiliadora Monteiro (org.) Gestão educacional: novos olhares, novas abordagens. Petrópolis, RJ: Vozes, 2005.

BARDIN, Laurence. Análise do Conteúdo. 3. ed., Lisboa, Portugal: Edições 70, 2004.

BRANDÃO, Carlos da Fonseca. LDB passo a passo: Lei de diretrizes e Bases da Educação Nacional (Lei no 9.394/96), comentada e interpretada, artigo por artigo. 2. ed. Atual. São Paulo: Editora Avercamp, 2005.

BRASIL. Secretaria de Educação Especial. Diretrizes gerais para o atendimento educacional aos alunos portadores de altas habilidades: superdotação e talentos. Ministério da Educação e do Desporto. Brasília: MEC/SEESP, 1995.

Resolução CNE/CEB no 2/o1 - Diretrizes Nacionais para Educação Especial na Educação Básica. Disponível em: http// www.mec.gov.br/seesp. Acesso em 12 de setembro de 2006.

. ABSD - RS. Constituição do Estado do Rio Grande do Sul. Manual de orientação para pais e professores. Porto Alegre: ABSD/RS, 2000.

Política Nacional de Educação Especial a perspectiva da Educação Inclusiva. Brasília: MEC/SEESP,2008.

GIL, Antônio Carlos. Métodos e técnicas de pesquisa social. 4. ed. São Paulo: Atlas, 1994.

LIBÂNEO, José Carlos; OLIVEIRA, João Ferreira; TOSCHI, Mirza Seabra. Educação Escolar: Políticas, estrutura e organização. 2. ed. - São Paulo: Cortez, 2005. - (Coleção Docência em Formação / coordenação Antônio Joaquim Severino, Selma Garrido Pimenta). 
LÜCK, Heloísa. Concepções e processos democráticos de gestão educacional. Petrópolis, RJ: Vozes, 2006. Série: Cadernos de Gestão.

LÜCK, Heloísa. Gestão educacional: uma questão paradigmática. Petrópolis, RJ: Vozes, 2006a. Série: Caderno de Gestão.

RENZULLI, Joseph S. O Que é Esta Coisa Chamada Superdotação, e Como a Desenvolvemos? Uma retrospectiva de vinte e cinco anos. In: Revista Educação. Porto Alegre - RS, Ano XXVII, n. 1 (52), Jan./Abr. 2004.

TRIVIÑOS, Augusto Nibaldo Silva. Introdução à pesquisa em ciências Sociais: a pesquisa qualitativa em educação. São Paulo: Atlas, 1987.

\footnotetext{
Tatiane Negrini

Educadora Especial/UFSM; Especialista em Gestão Educacional/UFSM e em Educação Especial: Altas Habilidades/Superdotação/UFSM; Mestre em Educação/UFSM.

E-mail para correspondência:

tatinegrini@yahoo.com.br

\section{Soraia Napoleão Freitas}

Prof $^{\text {a }}$ Dra. do Departamento de Educação Especial/UFSM. Líder do Grupo de Pesquisa Educação Especial: Interação e Inclusão Social - GPESP.
} 